\title{
CONCEPÇÕES ACERCA DA BIOLOGIA ENTRE DISCENTES DO ENSINO MÉDIO NO MUNICÍPIO DE CAJAZEIRAS - PARAÍBA
}

\author{
Danielly de Sousa Bezerra - Universidade Federal de Campina Grande - UFCG/CFP, \\ danibiologia20@gmail.com \\ Anderson Maciel Soares - Universidade Federal de Campina Grande - UFCG/CFP, \\ andersonmacielsoares@gmail.com \\ Jefferson Antônio Marques - Universidade Federal de Campina Grande - UFCG/CFP, \\ jeffymarques@gmail.com
}

\begin{abstract}
RESUMO
O estudo proposto tem como objetivo investigativo observar quais as concepções de estudantes do ensino médio sobre Biologia, sua relação com o dia-a-dia, além de refletir a forma como são trabalhados os conteúdos pela professora em suas aulas. O trabalho trata-se de uma pesquisa aplicada e de caráter qualitativo realizada por alunos do Centro de Formação de Professores da Universidade Federal de Campina Grande - CFP/UFCG. Os resultados apontam que a maior parte apresenta um conceito correto sobre a Biologia e gostam das aulas, e que uma pequena parte possui uma visão limitada e não gostam das aulas, e isso pode estar relacionado à forma como os conteúdos são abordados ou talvez não gostem da disciplina. $\mathrm{O}$ ensino tradicional ainda prevalece na maioria das escolas, onde a falta de inovação nas aulas de biologia, acaba levando ao desinteresse dos alunos pelos conteúdos, gerando pouca participação. Sendo assim, é necessário que os professores procurem utilizar novas estratégias para se trabalhar os conteúdos programáticos para uma melhor aprendizagem. A utilização de novos métodos e técnicas são vistos como o ponto de partida para o novo ensino que trabalha com os mesmos conteúdos, porém de forma mais didática e inovadora.
\end{abstract}

\section{PALAVRAS-CHAVE: Biologia; Ensino; Conteúdos.}

\begin{abstract}
The paper aims to investigate the conceptions of High School students about Biology and its relationship with daily life, as well as to reflect how the contents are worked by the teacher in their classes, as well as to consider how the contents are taught by the teacher during classes. This paper is an applied and qualitative research conducted by students of the Teacher Training Center of the Federal University of Campina Grande - CFP/UFCG. The results show that most students present a correct concept about biology and enjoy classes, and that a small part has a limited view and do not like the classes, and this may be related to the way the contents are approached or perhaps they do not like discipline. Traditional education still prevails in most schools, where lack of innovation in Biology classes ends up leading to students' lack of interest in content, generating low participation. Thus, it is necessary that teachers try to use new strategies to work on the contents of the program for better learning. The use of new methods and techniques are seen as the starting point for new teaching that works with the same contents, but in a more didactic and innovative way.
\end{abstract}

KEYWORDS: Biology; Teaching; Contents. 
INTRODUÇÃO

O Estágio como campo de conhecimento e eixo curricular central nos cursos de formação de professores possibilita que sejam trabalhados aspectos indispensáveis à construção da identidade, dos saberes e das posturas específicas ao exercício profissional docente (PIMENTA; LIMA, 2004). Segundo Barreiro e Gebran (2006), o estágio deve pautarse pela investigação da realidade, por uma prática intencional, de modo que as ações sejam marcadas por processos reflexivos entre os professores formadores e os futuros professores, ao examinarem, questionarem e avaliarem criticamente o seu fazer, o seu pensar e a sua prática.

A rejeição pelo ensino tradicional costuma expressar-se por parte dos professores em formação. No entanto, há evidências de que apesar de todas as repulsas verbais, hoje se continua fazendo nas aulas praticamente o mesmo que há 60 anos (CARVALHO; GILPÉREZ, 2011). Segundo Delizoicov et al. (2002), o ensino de Ciências e Biologia é um processo que se inicia no ensino fundamental e que se prolongam pela vida toda, as Ciências contribuem para a compreensão da realidade que nos cerca. Para Marins (2005), é relevante para o futuro professor o conhecimento de modelos teóricos surgidos na literatura que procuraram estabelecer alternativas metodológicas para o ensino de Biologia, levando-se em conta também a existência de concepções alternativas.

Em uma perspectiva mais ampla, deve-se assumir os focos da aprendizagem docente como valores gerais para a formação de professores como critérios qualificadores de uma boa formação indicando pontos fortes e fracos (ESCOLANO et al., 2010). Nas aulas de Biologia o ato de criar novas situações depende muito do envolvimento e da relação estabelecida entre o estagiário e os alunos durante sua atividade docente, o que compete ao futuro professor ousar, pensar o novo, reinventar e criar. Tais elementos devem surgir e ser aperfeiçoados no decorrer da profissão docente. Assim, faz-se necessário formar profissionais com senso crítico e que acreditam em mudança no contexto escolar (MILANESI, 2012).

Sua formação deve estar fundamentada na reflexão crítica sobre as práticas educativas e na (re) construção permanente de sua identidade, daí a importância do investimento na pessoa do professor e nos saberes advindos de sua experiência (NASCIMENTO, 2010). A expectativa dos estudantes em relação ao ensino que desejam traz a indicação de que a escola ainda trabalha com a perspectiva da pedagogia tecnicista, em que o processo educativo está 
organizado de forma objetiva e operacional, rejeitando a subjetividade dos sujeitos que constituem a escola (FRISON et al, 2002). O ser humano apresenta a tendência de aprender mais facilmente um corpo de conhecimentos quando ele é apresentado a partir de suas ideias mais gerais e mais inclusivas e se desdobrando para as ideias mais específicas e menos inclusivas (NASCIMENTO, 2010).

O professor deve incentivar para que haja em suas aulas um diálogo aberto, em que estudantes e o professor respeitem-se mutuamente, vendo o outro e vendo-se como agentes de mudanças que poderia trazer melhorias ao ambiente escolar. Inclusive proporcionando um aprendizado mais efetivo, uma vez que o envolvimento deles na própria aprendizagem tem relação com os modos de participação permitidos e incentivados (FRISON et al, 2002).

Portanto, o estágio supervisionado é o momento adequado para que o estagiário desenvolva competências transformando o seu estágio em uma atividade reflexiva, visando uma educação de qualidade e buscando cumprir o seu real papel de professor, o de tornar a escola cidadã, promotora da transformação social (BARROS et al., 2011). É o momento de começar a refletir sobre sua ação de construção e reconstrução da aprendizagem enquanto aprendiz inserido agora em uma formação continuada, necessária para realimentação do ciclo ação-reflexão-ação (MILANESI, 2012).

A vivência do estagiário no ensino médio é algo desafiador, principalmente nas aulas de Biologia, a busca por algo que motive o interesse dos alunos se torna uma tarefa difícil e preocupante. Os sentidos de ensinar Biologia estão muito atrelados a ideias que auxiliem os alunos a compreender os conceitos de ciência e a tecnologia como cultura e não de permitir que eles formulem sua própria definição. O futuro professor precisa, antes de tudo, enxergar as lacunas existes no ensino dessa área do conhecimento para que ele possa eliminá-las na sua atuação. É necessária uma educação que minimize o medo de inovar durante as aulas e que a procura por métodos e técnicas que contribuam para uma melhor aprendizagem seja mais frequente e não se reduzam apenas aos estudantes de graduação (SOARES; DINIZ, 2009).

De acordo com Giassi e Moraes (2009) o ensino de Biologia desenvolvido nas escolas ainda se mantém longe da realidade dos alunos devido ao seu caráter tradicional e continuísta. A educação contextualizada, em contraposição a esse tipo de ensino tradicionalista, incentiva a capacidade de pensar e agir de forma crítica e consciente do aluno não só na biologia, mas como também em outros componentes curriculares. A contextualização, portanto, passa a ser complementar ou igual à interdisciplinaridade; ou seja, permite uma ligação entre os sentidos 
quando referida como recurso para tornar a aprendizagem significativa e associá-la com experiência da vida cotidiana ou com os conhecimentos adquiridos espontaneamente.

Nesse sentido, a contextualização e a interdisciplinaridade buscam em comum propiciar aos estudantes conhecimento através da associação entre o cotidiano, teoria e realidade, com possibilidades de compreensão e ação (SOARES; DINIZ, 2009; GIASSI; MORAES, 2009).

Nessa perspectiva, o presente trabalho trata-se de uma pesquisa realizada por alunos do Curso de Licenciatura em Ciências Biológicas do Centro de Formação de Professores da Universidade Federal de Campina Grande - CFP/UFCG, na disciplina Estágio Supervisionado, com o objetivo de observar quais as concepções de estudantes do ensino médio sobre Biologia, sua relação com o dia-a-dia, além de refletir a forma como são trabalhados os conteúdos pela professora em suas aulas.

\section{METODOLOGIA}

A pesquisa foi realizada em uma Escola Estadual da rede pública de ensino, localizada no município de Cajazeiras, na Paraíba, em março de 2017, com o intuito de observar quais as concepções dos estudantes do ensino médio sobre Biologia, sua relação com o dia-a-dia, além de analisar como são trabalhados os conteúdos pela professora em suas aulas. A coleta de dados se deu por meio de questionários aplicados entre 25 alunos da turma do $2^{\circ}$ ano $\mathrm{C}$.

Em conformidade com Ferreira et al. (2012), do ponto de vista da sua natureza, esta pesquisa é do tipo aplicada, com abordagem de problema de caráter qualitativo. Quanto aos seus objetivos, é do tipo descritiva, visa descrever as características de determinada população ou fenômeno ou o estabelecimento de relações entre variáveis. Após a coleta, os dados foram analisados e discutidos, sendo comparados com trabalhos feitos por outros autores.

\section{RESULTADOS E DISCUSSÃO}

Para a realização deste trabalho escolheu-se aleatoriamente uma das turmas do ensino médio da Escola Estadual de Ensino Fundamental e Médio Professor Crispim Coelho, onde foi desenvolvido o estágio supervisionado nas aulas de Biologia. $\mathrm{O}$ uso de questionário para coleta de dados foi relevante, pois a partir dele pôde-se perceber a percepção da Biologia para 
os envolvidos, de forma a clarificar as ideias presentes nas respostas dos estudantes e compreender como esses entendem o conhecimento científico.

Esse entendimento por parte dos educandos influencia diretamente na forma como percebem e se relacionam com a Biologia e na sua aplicação durante o cotidiano social. Dentre os envolvidos referente à idade ela variou de 15 aos 18 anos.

Quanto a renda familiar, $60 \%$ dos alunos responderam que possuem uma renda de até 1 salário mínimos $(\mathrm{R} \$ 937,00)$ e 40\% de 1 até 3 salários mínimos (de $\mathrm{R} \$ 937,00$ à $\mathrm{R} \$ 2811$ ) como demonstrado no gráfico 01. É possível assim, verificar que a maioria dos alunos envolvidos na pesquisa estão enquadrados na classe de baixa renda, visto que suas famílias possuem uma renda mensal inferior a um salário mínimo, e isso pode ser comprovado pela ficha de matrícula do aluno.

Gráfico 01: Renda familiar mensal dos estudantes do $2^{\circ}$ ano C.

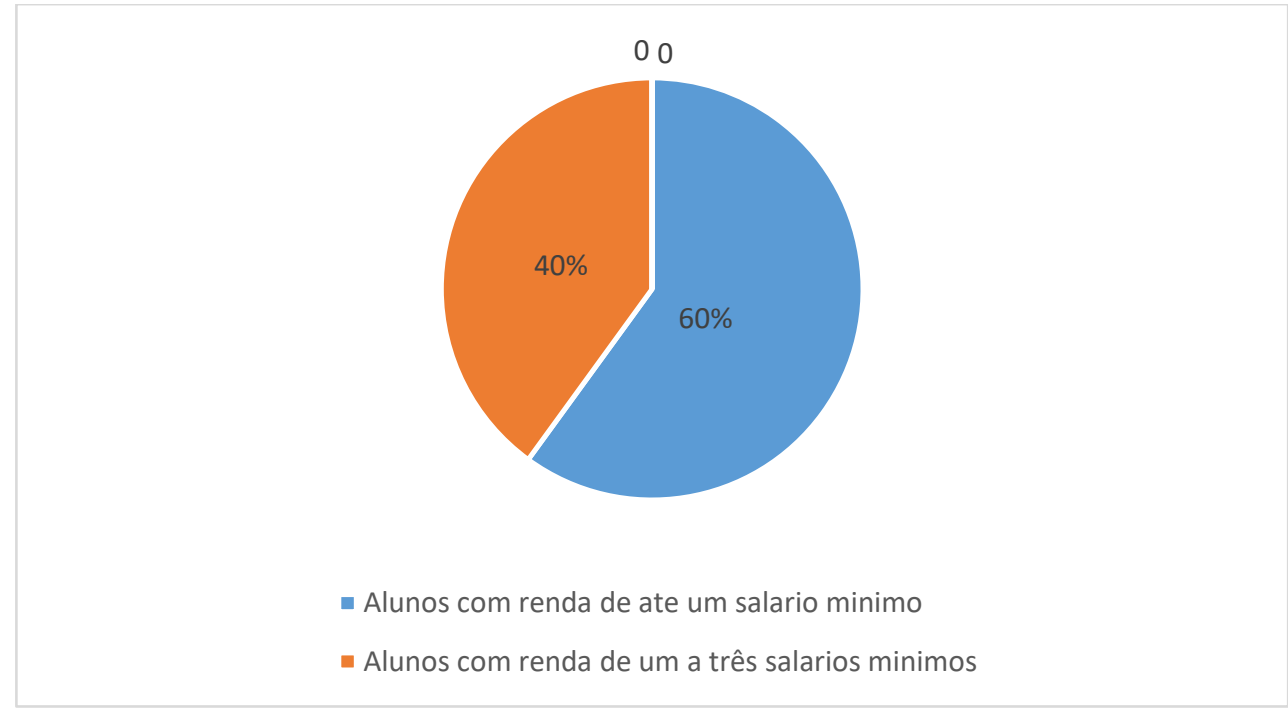

Fonte: Elaborado pelos autores, 2017.

Quando questionados sobre sua ocupação fora da escola; $68 \%$ afirmaram não possuir ocupação; $20 \%$ responderam que fazem curso de informática e $12 \%$ responderam que trabalham e fazem academia.

Quando solicitado aos alunos que apresentassem um conceito (uma definição) para Biologia, $76 \%$ dos alunos a definiram como "o estudo da vida"; $24 \%$, em suas respostas, classificaram como uma "disciplina de importância para ser humano, necessária para se 
estudar e onde nem tudo é verdade". Os resultados encontrados estão ilustrados no gráfico 02, a seguir.

Gráfico 02: Conceito dos alunos sobre Biologia.

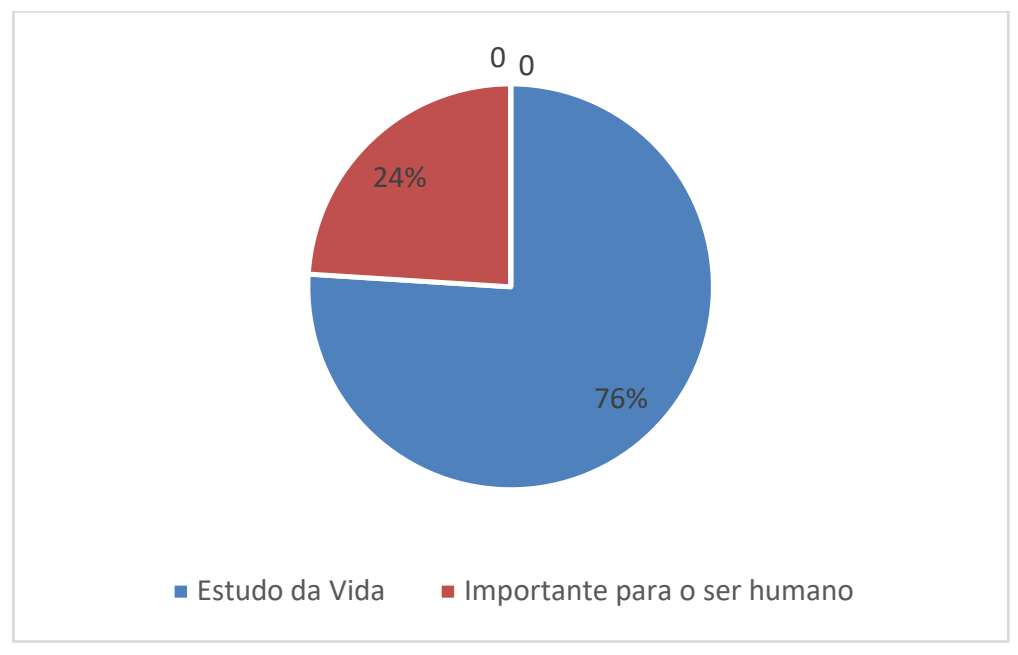

Fonte: Elaborado pelos autores, 2017.

Diante desses resultados é possível constatar que a maior parte apresenta conceito comum sobre a Biologia, e que uma pequena parte possui uma visão limitada. Segundo Bastos Junior (2013), essa disciplina contribui para a formação de cidadãos críticos e atuantes e, por isso, é importante que os professores se preocupem com sua prática, planejem suas aulas e mostrem aos alunos a importância da Biologia.

Quando indagado aos estudantes sobre como são as aulas e o que gostariam que mudasse; $20 \%$ responderam que as aulas são ótimas e que não precisam de mudança; $70 \%$ disseram que as aulas são boas, dentre as repostas destacaram, no entanto, queria que mudasse um pouco a forma das aulas, sendo interessante fazer mais visitas ao laboratório; e, por fim, $10 \%$ responderam que as aulas são ruins, carecendo ser menos repetitivas e com maior utilização de filmes durante as aulas (gráfico 03). 
Gráfico 03: Concepção dos alunos em relação às aulas.

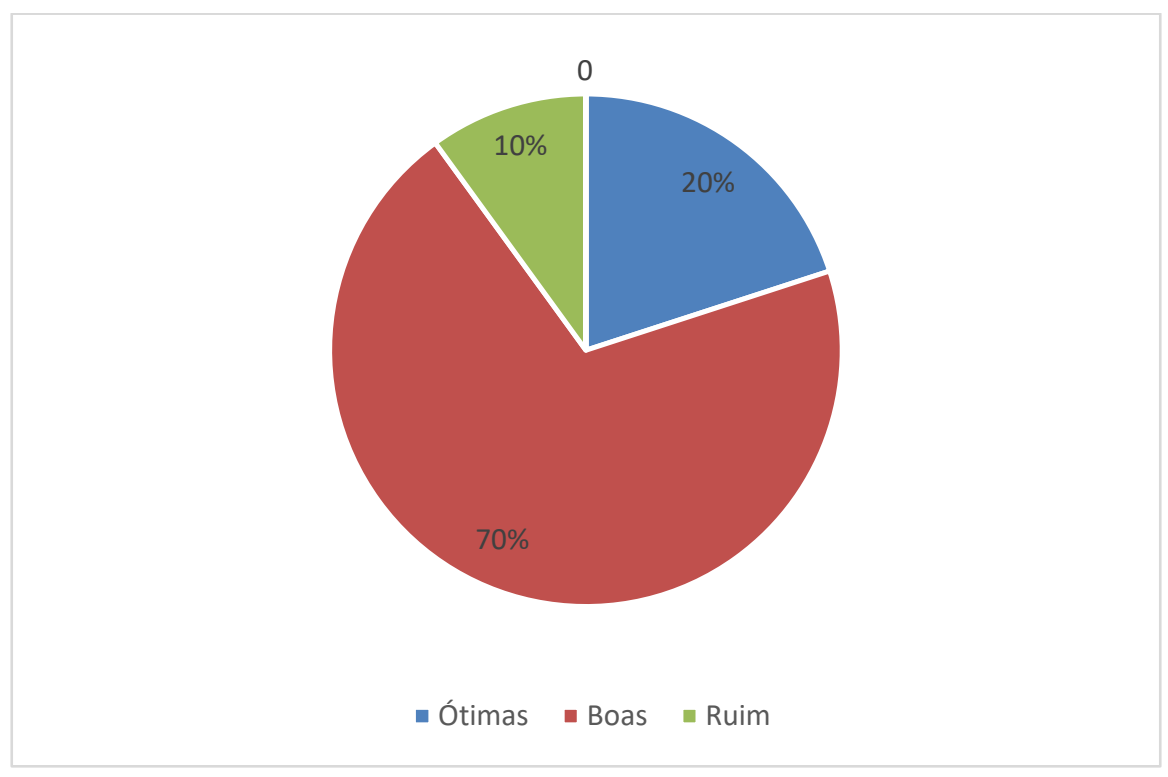

Fonte: Elaborado pelos autores, 2017.

A partir dos resultados é possível observar que a maioria dos alunos considera as aulas boas, e que uma pequena minoria considera que são ruins, e isso pode estar relacionado à forma como os conteúdos são abordados ou talvez esses alunos não gostem da disciplina. Um trabalho semelhante realizado por Sobrinho (2009), mostra que o ensino, na maioria das escolas, ainda acontece de maneira tradicional e as pesquisas nessa área, têm como foco o professor, a falta de uma formação qualificada, acaba influenciando na percepção dos alunos. Segundo o autor, quando o estudante gosta da disciplina ou conteúdo, mostra-se mais motivado com os estudos e esse esforço resulta em melhores resultados no seu desempenho.

Diante do questionamento acerca da relação entre Ensino de Biologia ensinado em sala de aula e o seu dia-a-dia, 60\% dos alunos identificaram a relação, dentre as respostas citaram, "está bastante presente na minha vida, em vários aspectos, como por exemplo, em relação às plantas, animais, o ser humano e saúde”. Os estudantes em suas respostas ainda enfatizaram dizendo que "estudar tudo isso faz com que se tenha consciência e entenda melhor a nossa relação com a natureza". Os outros $40 \%$ dos alunos não responderam ou afirmaram não entender essa relação.

Segundo Eloia e Eloia (2012), a Biologia é um campo das ciências que estuda a vida nas mais variadas formas e que está presente no dia a dia; no entanto, muitos alunos não a relacionam com o seu cotidiano e não reconhecem sua associação com as outras disciplinas. Um dos problemas mais comuns desse ensino, no Brasil, se relaciona com uma apresentação 
dos conteúdos de forma segmentada, o que acaba provocando nos alunos uma visão ingênua da Ciência e distante da realidade do trabalho científico.

Referente ao questionamento sobre quais assuntos e temas gostariam que fossem mais debatidos e melhor ilustrados na disciplina, 20\% responderam que gostaria que o corpo humano fosse mais trabalhado em aula, $12 \%$ plantas, $8 \%$ o espaço, $20 \%$ genética, $20 \%$ animais e $20 \%$ doenças (gráfico 04).

Gráfico 04: Assuntos requisitados pelos alunos para serem mais trabalhados em aula.

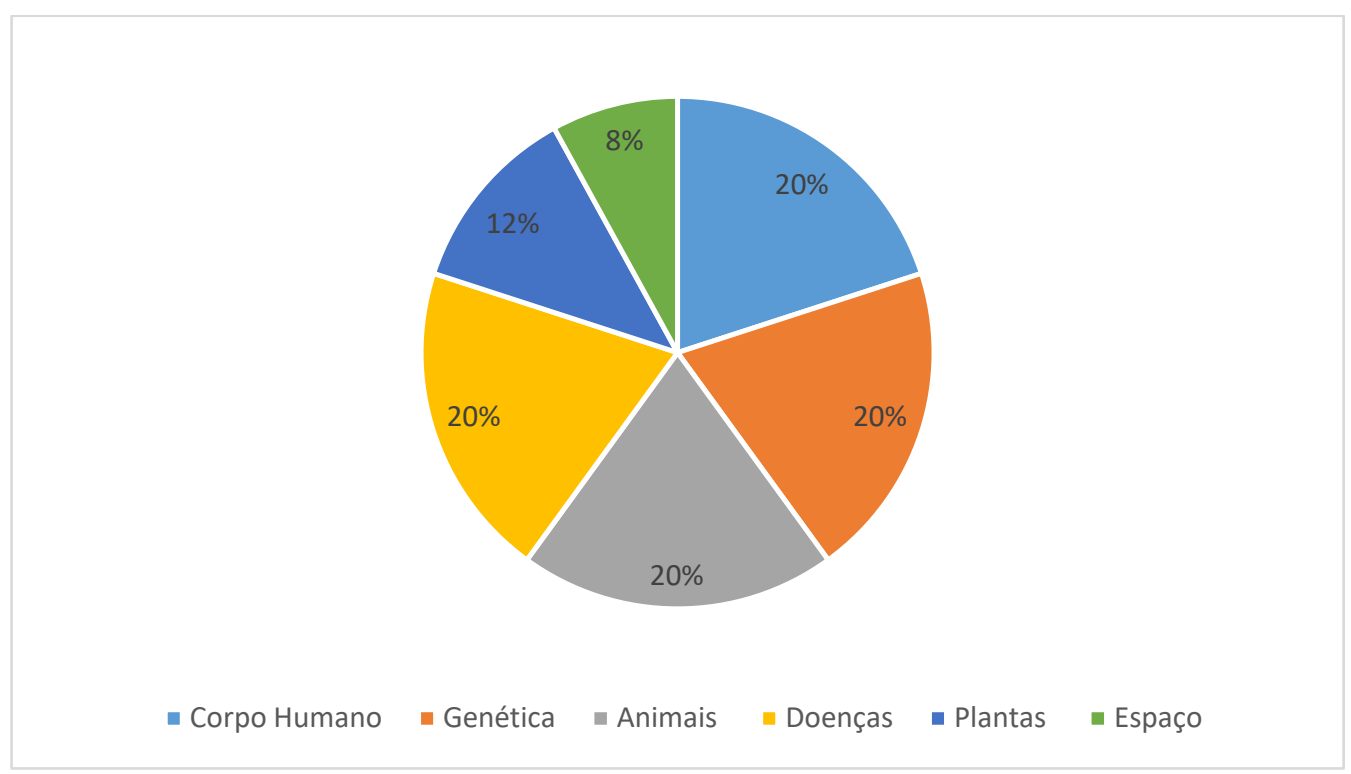

Fonte: Elaborado pelos autores, 2017.

Para Sobrinho (2009), o ensino tradicional com base apenas nos livros didáticos ainda vem sendo usados por muitos docentes em sala de aula. Com isso o autor defende modelos alternativos, denominados modelos cognitivos, que despertem o interesse dos alunos, as aulas devem ser mais debatidas e ilustradas, com uso de experimentação. O educador, mesmo contra o tempo, carência de recursos e demais condições em oposição, precisa de forma criativa trabalhar com mais ênfase a ciência.

\section{CONCLUSÃO}

Este trabalho foi desenvolvido a partir de observações realizadas nas aulas de Biologia do componente curricular Estágio Supervisionado. O estágio é um período importante na formação do futuro profissional e requer dos estagiários dedicação e empenho na sua 
realização. Nos cursos de licenciatura, possibilita a vivência da docência e uma aproximação do ambiente de trabalho almejado, ajudando o estagiário a formular uma posição sobre a atividade docente.

O ensino tradicional ainda prevalece na maioria das escolas, onde a falta de inovação nas aulas de biologia, acaba levando ao desinteresse dos alunos pelos conteúdos, gerando pouca participação. A partir dos resultados é possível observar que os estudantes mostram-se muito presos as definições repetidas, além de estarem acostumados ao padrão tradicionalista de aula, sem modificações.

Sendo assim, é necessário que os professores procurem utilizar novas estratégias para se trabalhar os conteúdos programáticos para uma melhor aprendizagem dos alunos. A utilização de novos métodos e técnicas são vistos como o ponto de partida para o novo ensino que trabalha com os mesmos conteúdos, porém de forma mais didática e inovadora.

Por fim, o estágio supervisionado é essencial nos cursos de licenciatura, uma vez que permite ao estagiário uma aproximação com o futuro ambiente de atuação e reflexão sobre suas próprias práticas. Além disso, auxilia a diagnosticar problemas no ambiente escolar como um todo e ponderar, apresentar soluções; pesquisar e aplicar novas metodologias de ensino e aprendizagem.

\section{REFERÊNCIAS}

BARREIRO, I. M. de F.; GEBRAN, R. A. Estágio curricular na formação de professores: Propostas e possibilidades no espaço escolar. In: Prática de Ensino e estágio supervisionado na formação de professores. São Paulo: Avercamp, 2006. p. 87-115

BARROS, J. D. S; SILVA, M. F. P; VÁSQUEZ, S. F. A prática docente mediada pelo estágio supervisionado. Atos de Pesquisa em Educação, v. 6, n.2, p. 510-520, maio/ago. 2011.

BASTOS JÚNIOR, P. de S. Metodologias e estratégias utilizadas para o ensino de Zoologia. 2013. 24f. Trabalho de Conclusão de Curso (Licenciatura em Ciências Naturais) Faculdade UnB Planaltina, Planaltina - DF, 2013.

CARVALHO, A. M. P. de; GIL-PÉREZ, D. Necessidades formativas do professor de Ciências. In: Formação de professores de Ciências: tendências e inovações. 10 ed. São Paulo: Cortez, 2011. p. 9-64. 
DELIZOICOV, D.; ANGOTTI, J. A.; PERNAMBUCO, M. M. Desafios para o ensino de Ciências. In: Ensino de Ciências: Fundamentos e Métodos. São Paulo: Cortez, 2002. p. 31-42.

ELOIA, S. M. C.; ELOIA, S. C. A importância da disciplina de biologia associada à vida saudável na visão dos estudantes. Essentia Sobral, v. 13, n. 2, p. 81-94, dez. 2011/maio 2012.

ESCOLANO, A. C. M.; MARQUES, E. de M.; BRITO, R. R. de. Utilização de recursos didáticos facilitadores do processo ensino aprendizagem em Ciências e Biologia nas escolas públicas da cidade de Ilha Solteira/SP. In: Congresso Internacional de Educação, 02, 2010, Ponta Grossa-PR. Anais... Ponta Grossa, Paraná. 2010. 16 p.

FERREIRA, L. B. et al. A técnica de observação em estudos de administração. In: Encontro da Associação Nacional de Pós-graduação e Pesquisas em Administração, 36, 2012, Rio de Janeiro - RJ. Anais... Rio de Janeiro: ANPAD, 2012. Online.

FRISON, M. D. VIANNA, J. RIBAS, F. K. Ensino de Ciências e aprendizagem escolar: manifestações sobre fatores que interferem no desempenho escolar de estudantes da educação básica. In: ANPED SUL: seminário de pesquisa em educação da região sul, 09, 2012. Caxias do Sul, Anais...Caxias do Sul, 10p.

GIASSI, M. G.; MORAES, E. C.; A contextualização no ensino de biologia: Abordagens preliminares. $2009 . \quad$ Disponível em: <http://www.nutes.ufrj.br/abrapec/vienpec/CR2/p1116.pdf >. Acesso em: 15 de julho de 2017.

MARTINS, A. F. P. Ensino de ciências: desafios à formação de professores. Revista Educação em Questão, v. 23, n. 9, p. 53-65, maio/ago. 2005.

MILANESI, I.; Estágio supervisionado: concepções e práticas em ambientes escolares.

Educar em Revista, n 46, p. 209-227, out /dez. 2012.

NASCIMENTO, F. FERNANDES, H. L. MENDONÇA, V. M.O ensino de ciências no Brasil: história, formação de professores e desafios atuais. Revista HISTEDBR On-line, Campinas, v 10, n.39, p. 225-249, 2010.

PIMENTA, S. G.; LIMA, M. L. Estágio e Docência. São Paulo: Cortez. 2004.

SOARES, M, N. DINIZ, R. E. S.; Sentidos sobre o ensino de biologia: considerações críticas a partir das vozes dos licenciados In: Encontro Nacional de Pesquisa em Educação em ciência, 7, 2009, Florianópolis - sc. Anais... Florianópolis, Santa Catarina, 2009.

SOBRINHO, R de. S. A importância do ensino da biologia para o cotidiano. 2009. $40 \mathrm{f}$. Monografia (Licenciatura em Biologia) - Faculdade Integrada da Grande Fortaleza, Fortaleza - CE, 2009. 
